\title{
Um arlequim jamais terminado. Teatro, juventude e direito à cultura na periferia francesa
}

\author{
Mione Apolinario Sales \\ Universidade do Estado do Rio de Janeiro (UERJ)
}

Um arlequim jamais terminado. Teatro, juventude e direito à cultura na periferia francesa

Resumo: Este artigo consiste numa análise do filme A esquiva (França, 2003), de Abdellatif Kechiche, que narra como estudantes da periferia montam uma peça de teatro. $\mathrm{O}$ foco repousa sobre o modo de vida e a linguagem desses adolescentes, tendo como pano de fundo a problemática do direito à cultura. Para essa abordagem, foi feita uma pesquisa qualitativa, de natureza exploratória, na internet, a partir de arquivos disponíveis sobre o filme, desde 2003. A análise teve por base textos da crítica cinematográfica especializada e a reação dos espectadores em fóruns de discussão on-line, em sites franceses.

Palavras-chave: Teatro. Juventude. Direito à cultura. Cinema. Questão social.

\section{An Unfinished Harlequin. Right to Culture, Theater and Youth in the French Periphery}

Abstract: This article presents an analysis of the film A esquiva (France, 2004), by Abdellatif Kechiche, which narrates how students from the periphery mounted a theatrical play. It focuses on the way of life and language of these adolescents. The background is the issue of the right to culture. A qualitative study of an exploratory nature was conducted on the Internet, based on files available about the film since 2004. The analysis is based on specialized film criticism texts and the reaction of spectators in on-line discussion forums found in French sites.

Key words: Right to culture. Youth. Cinema. Theater. Social issues. 


\section{Começo de sessão - O que incomoda é o que faz pensar $^{1}$}

Choque do estranho, choque da estranheza, Choque do estrangeiro. Antes de mais nada, é a doxa que é atingida, a opinião que tenho sobre 'mim', a opinião que tenho sobre 'o outro'. Jean Borreil

A reflexão a ser compartilhada traz em seu centro a relação entre juventude e cultura, por meio de uma abordagem cinematográfica crítica e inovadora, que pretende ir além das controvérsias e armadilhas sociais da violência. No contexto da mundialização e também de crise econômica, a experiência francesa torna-se referência paradigmática e desafiadora, por exigir um novo olhar para a juventude das periferias urbanas. A complexidade das dimensões étnico-raciais e de gênero mais a tensa e em constante transformação fase da adolescência somam-se subjetiva e objetivamente, requerendo dos profissionais e pesquisadores mediações originais que contribuam para pensar e responder, sob novos ângulos, as demandas desse segmento. É ao que se propõe o artigo em tela, recorrendo à potencialidade do cinema em aferir, na contemporaneidade, o drama da questão social e fecundar perspectivas humanizadoras mais auspiciosas. No filme analisado, a problemática da linguagem é a peça-chave desse quebracabeça intergeracional e social.

A esquiva ${ }^{2}$ (L'esquive) foi o segundo filme do diretor Abdellatif Kechiche. O conjunto de sua obra cinematográfica, composta de quatro bem sucedidos longa-metragens (La faute à Voltaire, 2000 ; La graine et le mulet, 2008; Venus noire, 2010), aborda o assunto da imigração e problemas correlativos. Mesmo pondo em foco a questão social ${ }^{3}$, o autor faz escolhas que enriquecem os conhecimentos críticos e estéticos de quem assiste aos seus filmes, ao propor abordagens inéditas do cotidiano.

Em A esquiva, que narra a história de um grupo de adolescentes moradores de uma cité $^{4}$ na periferia parisiense, o cineasta optou por um procedimento sofisticado de relato, a mise en abyme (DALLËNBACH, 1977). Esta estratégia artística consiste em superpor técnicas e situações ou uma história dentro da outra, tanto na literatura quanto no teatro e no cinema ${ }^{5}$. No filme analisado, ela é mobilizada quando se insere a realização de uma peça de teatro - O jogo do amor e do acaso, de Marivaux (1688-1763) ${ }^{6}$ - no seio da trama cinematográfica. Logo, o "espectador" é também duplamente envolvido nessa lógica de "espelho": assiste a um filme e a uma peça de teatro, simultaneamente, ou seja, de maneira superposta. E essa é a intenção do autor.

O espectador, leigo ou não, se está esclarecido sobre o que se passa, não deixa de experimentar certo estranhamento, porque essa escolha rompe com as expectativas do senso comum sobre o cinema como ilusão ou reprodução da realidade ${ }^{7}$. A esperança do diretor, por sua vez, é a de um envolvimento maior daquele que assiste, donde o desvelamento das técnicas. Dentro dessa ótica, o filme não quer mascarar nada. Uma das primeiras cenas envolve, por exemplo, a definição de um dos itens do "figurino" da peça de teatro. A cena mostra a ida da personagem Lydia ${ }^{8}$ a um costureiro, lá mesmo na cité, onde foi buscar seu traje de cena, cujo preço tentou regatear até o último minuto. Não conseguindo, pede dinheiro emprestado a Krimo ${ }^{9}$, um colega de classe, igualmente protagonista, o qual será seu "par amoroso" dali para frente. Ele a encontra por acaso às voltas com essa situação, empresta-lhe o dinheiro que falta e fica extasiado com a sua beleza.

O contraste estético, portanto, é evidente: uma bela e jovem estudante, atriz amadora de teatro e vestida à moda do século 18 , desfila vivaz pelas ruas do conjunto habitacional, com sua aridez urbana de enormes prédios $\operatorname{cinzas}^{10}$. A personagem veste-se como aristocrata, mas, paradoxalmente, não tem como pagar uma roupa de luxo. Todos esses detalhes exacerbam a tensão entre a questão social e o direito à cultura $^{11}$, ficando o espectador com a sensação de que alguma coisa está fora da ordem. Há um choque de época e lugar, não obstante o encontro desafiante entre uma trupe banlieuesarde de jovens atores amadores e as exigências do teatro "iluminista".

O público, se adere à proposta e aceita entrar no "jogo", é convidado a participar virtualmente dos ensaios, que envolvem brigas e confrontos verbais, pelo entendimento de como representar o texto: disputas de forma e de sentido. A cada estratégia desvendada, o espectador interage, então, mais e mais com a narrativa. Contudo, o que o incomoda, a princípio - e por isso o leva a pensar -, é saber-se no cinema e no entanto ter a sensação de "teatro (ensaios) dentro do teatro (representação)", na medida em que boa parte das cenas gira em torno da preparação da peça, ao ar livre ${ }^{12}$.

Quem exerce moderadamente a função de diretora da peça é a professora de francês ${ }^{13}$, na ocasião dos ensaios em sala de aula. Registre-se sua perseverança pedagógica e o êxito da sua iniciativa, enquanto mestre de um colégio da periferia francesa, que consegue envolver a classe em um projeto apaixonante, ainda que, a princípio, aparentemente irrealizável. Desse modo, essa personagem responde ao drama da violência na escola pública, vencendo a desmotivação e a falta de projeto educacional quando muitos professores, aqui e alhures, diante de situações educativas complexas, simplesmente desistem.

Não obstante, A esquiva é acima de tudo uma experiência de cinema, com um roteiro bem definido as réplicas da peça, por exemplo, misturam-se, com 
perfeição, aos diálogos travados entre os jovens atores -, embora, como sugere o título da peça, prevaleça a sensação de jogo e de improviso. As opções cinematográficas de A. Kechiche, inspiradas em Marivaux, podem levar a que, indevidamente, avaliese o que é uma técnica de direção com falta de preparo dos atores. Na verdade, tudo ali é codificado, nada é aleatório. Sabe-se ainda que o dramaturgo francês, fiel ao espírito da comedia dell'arte, privilegiava as improvisações gestuais, a vivacidade, o movimento e o ritmo. Kechiche, por sua vez, faz cinema seguindo a mesma cartilha. Diz ele:

\section{De um lado, esta atenção particular em tratar com fineza os sentimentos humanos, no que têm, ao mesmo tempo, de complexo e universal; e de ou- tra parte, o lugar acordado às 'pessoas humildes' por Marivaux. [Nas suas peças], [...], empregadas domésticas, camponeses, órfãos têm não somen- te um lugar especial na intriga, mas ele lhes em- presta igualmente uma vida íntima, uma interioridade, sentimentos nuançados [...]. A fun- ção que ocupam não basta para lhes definir. Isto é o que constitui, na minha opinião, a modernidade do seu olhar, seu caráter, até, de certa maneira, subversivo ${ }^{14}$.}

Eis por que os atores foram escolhidos entre os moradores da cité, de forma a possibilitar a visualização dessa juventude, ancorada numa época e cultura precisas, e também em sua porção humana. A escolha de trabalhar com esses jovens amadores, sem dúvida, conferiu ao filme um fôlego quase mágico. Ademais, rodar uma fita em que se representa uma peça do século 18 com uma dicção da periferia é audacioso e surpreendente ${ }^{15}$. Há apenas uma atriz profissional, Sara Forestier, no papel da adolescente Lydia, a qual interpreta, na peça, a doméstica Lisette; personagem que, segundo um estratagema e "jogo do amor", trocará de lugar com a sua patroa, Sylvia.

A espontaneidade e o natural na "pintura dos seres e das coisas" (ETERSTEIN, 1984, p. 10) são deliberadamente buscados por ambos autores como parte de uma "nova estética de sugestão", isto é, nem tudo precisa ser dito. Assim, de fato, a escolha da obra do dramaturgo do século 18 não se deu por acaso. Kechiche identifica-se com as rupturas propostas por Marivaux frente ao teatro do seu tempo, em particular com as características do seu trabalho: espírito crítico, observação da vida social, gosto da novidade e ênfase no poder das palavras. Pode-se acrescentar ainda o caráter progressista e nada moralista de suas peças, cheias de hu- mor e de crítica aos costumes da época. Intui-se que Kechiche partilha também da mesma utopia não pessimista de Marivaux, a de que, apesar das diferenças sociais de classe, que têm dividido historicamente os franceses, há ainda na contemporaneidade um lugar para o talento da juventude francesa da periferia no mundo da arte.

\section{Juventude, cultura e periferia: essa "terra estrangeira"}

Ao invés de insistir na representação da juventude pobre pelo ângulo da violência, como o já clássico longa-metragem francês, $O$ ódio (La Haine, 1995); ou pelo viés da crise social e do desnorteamento de adultos e instituições frente a ela, como é o caso do documentário-ficção francês Entre os muros da escola (Entre les Murs, 2008) ou o documentário brasileiro Pro dia nascer feliz (2006), Kechiche oferece um registro autêntico da cultura juvenil, com seus valores e modo de vida (pudores, amores, amizades, entre outros). A esquiva não deixa de ser, assim, uma ficção, mas tem também ares de documentário, em função da procurada naturalidade estética.

$\mathrm{O}$ diretor investe num drama em que a vida dos adolescentes está no cerne, com o cuidado, porém, de evitar um enfoque paternalista ou idealizado. Mesmo se há cenas duras, com disputas e "quiproquós" entre eles, em ritmo frenético - alguns marcados por intensa violência, até física - o filme resguarda o humor e a vivacidade típicos da adolescência. $\mathrm{O}$ diretor esclarece por que escolheu registrá-los sob esse ângulo da brutalidade no diálogo: "Eu queria desmistificar esta agressividade verbal e fazê-la aparecer na sua verdadeira dimensão de código de comunicação" ${ }^{16}$. Seguramente, Kechiche teve êxito em explorar a inventividade e a arte do "palavreado" dos adolescentes da periferia, quase sempre encarado com desconfiança ou desprezo por terceiros. Pouco explorada pelo cinema até então, a criativa linguagem dos jovens da periferia pede passagem e conquista legitimidade.

É o que descreve também um espectador a respeito do efeito perturbador entre reportagem e ficção alcançado por Abdellatif Kechiche, em especial quanto aos constantes confrontos verbais e físicos, mais insultos inimagináveis, emblemáticos da nova geração de jovens da periferia: "[esses jovens] acotovelam-se o tempo todo para ver quem grita mais alto, sendo assim capaz de se impor [...]"17.

Trata-se, portanto, de um filme sobre adolescentes e que pode ser visto com vivo interesse pelos seus pares, na medida em que o autor procurou ser fiel ao 
espírito das "novas gerações" da periferia: metade francesas metade magrebinas ${ }^{18}$, logo pós-colonialistas e bastante mundializadas.

$\mathrm{O}$ diretor aceitou, assim, o desafio de percorrer a "terra estrangeira", na qual a juventude ${ }^{19}$, progressivamente, tem se transformado, aos olhos de pais, professores e educadores, especialmente num país como a França, em que a periferia de cidades como Paris ou Marselha agrupa inúmeras nacionalidades. Num simples HLM, coexistem pessoas, por vezes, de até 100 países de origem. Logo, à complexidade de decifrar a "juventude", que ganhou, ao longo do século 20, cada vez mais densidade social e histórica (ABRAMO, 1994), soma-se, na contemporaneidade, a exigência de compreender aquele extrato de jovens sobre o qual pesam fortes estigmas sociais e culturais (SALES, 2007).

Em decorrência de um racismo latente, que se acirra num contex to de profundas transformações do capitalismo, com reestruturação produtiva, deslocalizações, crise econômica e desemprego, sociedades europeias como a francesa têm cada vez mais temido a figura do "estrangeiro" (PORTEVIN et al., 2011), pobre ou de origem modesta. Este é visto como o diferente, o quem vem de fora, o bárbaro, o não civilizado. Por vezes considerados como seres inferiores, com dificuldades de adaptação, hábitos primitivos e sem domínio da língua escrita ou falada do país de acolhida, muitos dos imigrantes são, de fato, o excedente da França colonial, o que sobrou e veio à tona dos processos de dominação imperialista na África, Antilhas e Ásia.

Contudo, a mão de obra dessa população, em especial magrebina, revelou-se historicamente importante para as demandas do processo de produção econômica, sobretudo nos anos 1950, tendo sido absorvida como um "mal necessário". Seus filhos e netos tiveram acesso à cultura francesa e aos valores republicanos, muito embora desenvolvam estratégias de resistência cultural e ajam com despojamento e certa rudeza, como signo de questionamento do que subsiste ainda de preconceito e dominação colonial na pátria de Voltaire. É natural, portanto, que os jovens incorporem abertamente o sotaque árabe e invistam no verlan - gíria da periferia que promove a abreviação e inversão de palavras -, o qual tem se expandido para além das fronteiras "bárbaras" ${ }^{20}$. Os personagens de A esquiva pertencem, assim, à terceira geração de beurs ${ }^{21}$.

Romper com os estereótipos em torno da juventude banlieusarde é, pois, um dos objetivos de A esquiva que Kechiche alcança com a ajuda de Marivaux. Esse autor, pertencente ao florescente século do Iluminismo, movia-se também na contracorrente, turvando as águas teatrais em que nadavam de "braçada" precursores clássicos como Molière, Racine e Corneille. Para começar, ele irá preferir, à moda do Renascimento, mirar-se na expe- riência estrangeira da Itália, inspirando-se na produção teatral da commedia dell'arte. Suas peças contarão sempre no elenco com uma trupe de atores italianos. Não obstante, Marivaux, com suas comédias, inovou e diversificou a pauta teatral e tornou-se um dos ícones do teatro francês.

Por tudo isso, o filme de Kechiche quebra o protocolo e concede o direito à juventude pobre de encenar o teatro do século 18 em plena cité. Esta ousadia seduziu os jurados do prêmio da Academia das Artes e Técnicas do Cinema, que lhe conferiram quatro "Césars", em 2005: melhor filme, melhor diretor, melhor roteiro original ou adaptação ${ }^{22}$, e melhor jovem esperança feminina.

A categoria "tradução cultural" 23 , de Butler (2008), pode, nesse sentido, ser mobilizada para fins de conexão com os objetivos filosófico-estéticos, éticos e mesmo políticos pretendidos pelo filme. Poderia parecer evidente o direito à cultura num país como a França, no entanto há outros fatores subjacentes. Se considerarmos a presença expressiva de estrangeiros, originários ou não das ex-colônias, e massivamente de franceses de origem magrebina, a noção de "direito à cultura" pode se chocar com a de "direitos culturais" ${ }^{24}$. Estes direitos foram um dos últimos a ser objeto de regulamentação, após a Declaração Internacional dos Direitos do Homem de 1948. As polêmicas e resistências europeias giram em torno do risco de sua interpretação como invocação do direito à diferença cultural, ou seja, uma possibilidade de reforço do "comunitarismo" e das "tendências identitárias". Ao invés da partilha e da livre fruição de um direito de todos ao acesso a um patrimônio universal - relativo à cultura e valores ocidentais, mais todos os equipamentos públicos a ele concernentes -, os que divergem dos direitos culturais os entendem como a valorização de certas práticas (como a poligamia e a infibulação, frequentes entre os imigrantes africanos; ou o uso do véu e, até pouco tempo atrás, a burka entre os mulçumanos e fundamentalistas árabes), que podem colocar em risco conquistas democráticas ${ }^{25}$.

Mesmo se o filme se passa na França contemporânea e se os atores/personagens nasceram e foram educados ali, sob a influência das instituições e valores republicanos, os espectadores sentem forte estranheza, por não se reconhecerem na tela, especialmente no que concerne à língua falada ou língua viva: o francês com ritmo e sotaque árabe.

\section{A esquiva - jogo do amor, máscaras e relações de gênero}

O roteiro da ficção em tela escapa aos clichês de filmes violentos sobre a periferia francesa - que a retratam apenas como uma região sem direitos e de incivilidade, cheia de traficantes de drogas, jovens in- 
fratores e rappeurs. A película analisada, em contrapartida, aborda um tema universal, de Shakespeare aos nossos dias: o amor na adolescência. Na companhia de Marivaux - mestre das paixões humanas -, Kechiche vai conseguir mostrar que pouca coisa mudou nesse tipo de drama romântico, envolvendo garotos e garotas, ao longo dos séculos, embora as regras de amor numa cité sejam, em certos aspectos, mais complexas. Os papéis de gênero entre os adolescentes têm sido objeto, inclusive, de novas demarcações territoriais em reforço às identidades de sexo (PASQUIER, 2010).

A escolha do problema da linguagem ${ }^{26}$ intercultural, intergeracional e interclasses - como mediação cinematográfica seguramente deu originalidade à montagem, combinada à escolha do texto de Marivaux - trabalhado, de forma alegórica, em paralelo -, o que confere também unidade ao filme. Os personagens principais, Lydia e Krimo, são colegas de classe e vão se enamorar ao longo da história, duplamente, como protagonistas de A esquiva e como atores da peça $O$ jogo do amor e do acaso, encenada dentro do filme. Ela será Lisette, ele Arlequim. Na verdade, Krimo vai convencer outro colega, $\mathrm{Nanou}^{27}$, a lhe deixar esse papel, pois, tímido, acredita que conseguiria por meio do texto da peça ter coragem de confessar o seu amor à Lydia. A estratégia vai se revelar um fracasso, diante da amplitude do texto e do trabalho de cena exigido. $\mathrm{O}$ jovem, que certamente tocou o coração de Lydia, não tem, porém, talento algum para o jogo teatral.

Se enxergarmos o que sucede a Krimo pela lógica da maurivaudage, constataremos que não basta trocar as máscaras, ou seja, de papéis e lugares com outros, visto que não se altera a essência do que se é apenas por uma nova aparência. Logo, se o disfarce e a consequente troca de identidade fazem parte do teatro, favorecendo a representação de uma personagem, a utilização de "máscaras" não chega a ser, como demonstra a peça, uma aventura sem risco. Trata-se de uma atividade imaginativa extraordinária, mas complexa. Krimo, ao se apoderar do traje de Arlequim, persegue a intencionalidade original da peça de Marivaux: a revelação do amor, não obstante o expediente momentâneo de uma mentira ${ }^{28}$. Todavia, o filme emancipa-se da peça, na medida em que Krimo é um jovem bonito, mas melancólico e silencioso. Seu pai encontra-se preso e ele mora apenas com a mãe. Nem mesmo o amor vai fazê-lo romper com as amarras da sua personalidade discreta e transformá-lo num exuberante Arlequim. Pode-se imaginar que, para o jovem, o amor pertence à ordem dos discursos passíveis de engano (BUTLER, 2004). Nesse sentido, a linguagem pode até suscitar o desprezo de outrem, na medida em que sentimento e discurso nem sempre correspondem. Por isso, ele optou por se esconder atrás do personagem de Arlequim. A ambiguidade da situação, entre o real e a ficção, pouparia a vergonha, caso ele sofresse uma "esquiva".

Se o diálogo flui entre os adolescentes na conversa entre os amigos, inclusive em momentos de disputa acirrada, ele perde o seu dinamismo quando o assunto é amor. Segundo Eterstein (1984), a linguagem também funciona como uma segunda máscara e, no caso de Krimo, ele não consegue se desvencilhar dela. Lydia somente pouco a pouco compreende o que o colega sente por ela, pois como a opacidade e a dificuldade de comunicação de Krimo são muito fortes - alternando gestos mudos e desajeitados a uma fala também desajeitada $^{29}$-, ela não chega muito bem a entender o que se passa até a intervenção de um dos amigos, Fathi ${ }^{30}$, que insiste que ela dê uma resposta clara.

Cria-se, então, um impasse: o "enamorado" não consegue se exprimir corretamente e a "enamorada" não sabe ao certo o que ele quer, mesmo assim é pressionada pelo amigo a se posicionar. Através dessa manipulação, delineia-se o machismo árabe, um dos elementos culturais que particularizam e tensionam as relações de gênero ${ }^{31}$ nas cités. Fathi desempenha uma espécie de "função paterna", primeiramente, tentando reconciliar o amigo com sua ex-namorada, Magalie ${ }^{32}$. Vencido pela paixão silenciosa de Krimo e admitindo que ele ama Lydia (il l'a kiffe, em verlan), Fathi tenta, por todos os meios, proteger o amigo da dúvida e do grau de exposição a que o jogo amoroso comporta. É como se o amor fosse uma armadilha da qual os adolescentes tentam se "esquivar" a todo preço, isto é, não se render $^{33}$. Com o álibi da solidariedade, Fathi age, por exemplo, com extrema violência e ameaça Frida (Sabrina Ouazani), uma das amigas de Lydia, para que ela interceda e esta última dê uma resposta logo a Krimo. Em seguida, é a própria Lydia que entra na ciranda da pressão masculina. O apoio de Fathi tem, assim, um peso sufocante. Como antítese da figura "minimalista" de Krimo, sua personagem caracterizase pelo excesso verbal e comportamental.

Lydia, tal qual o espectador, gostaria apenas de ter um pouco mais de tempo para pensar. Ela ainda não está pronta para dar uma resposta, mas o tempo do coração masculino urge. Contra os preconceitos e reducionismos de muitos que a enxergam de longe, Kechiche consegue mostrar que a juventude da periferia vive sentimentos e conflitos universais, não obstante a dura realidade social e econômica cotidiana.

Diante de tantas interferências externas, o "jogo do amor" perde, assim, toda a sua naturalidade e espontaneidade. Não por acaso, nessa atmosfera opressiva de predominância de gênero e de falta de liberdade, ocorre a cena da batida policial. Lydia é interrompida, antes de responder. O silêncio ou o indizível coroa o desfecho do que deveria ser a revelação - ou seja, a resolução do conflito e da dúvida amorosa, o fim da espera visto que os jovens serão presos. Lydia persiste em seu projeto de ser atriz e entra em cena, bem como os 
demais colegas. Krimo, por sua vez, "esquiva-se" ${ }^{34} \mathrm{e}$ sequer comparece ao espetáculo do colégio. Ele cumpre, portanto, segundo Borreil (1993, p.145), o destino de ser "um arlequim jamais terminado".

Se percebermos bem, há no filme uma inversão de papéis. É o mocinho que se apaixona, é passivo, frágil e tímido; traços de personalidade que fogem completamente ao estereótipo da virilidade árabe. Por isso, ele necessita ser protegido pelo brother (mon pote). Diante da necessidade de tempo de Lydia, que lhe parece intolerável, Krimo esquiva-se, reagindo, mais uma vez, de maneira "feminina" ou românticosofredora, qual o imortalizado personagem Werther, de Goethe. O filme retrata, pois, a complexidade das relações amorosas na adolescência, em meio aos HLM. O amor mostra assim que não cabe nos limites de nenhum gueto. Faz a alma aspirar à liberdade, tão ansiada pelo personagem de Krimo e de seu pai, que da penitenciária envia, regularmente, belos desenhos e pinturas de barcos à vela.

Lydia, a personagem do filme, é, por sua vez, fiel ao perfil das heroínas de Marivaux. À sua maneira, afirma o seu desejo e a necessidade de que respeitem também o seu jeito e o seu tempo. Com uma personalidade afirmativa, tem êxito na peça, e embora saia um pouco frustrada em relação ao que foi quase um namoro, encerra o filme andando livre pelas ruas da cité. Nem a dominação masculina nem a questão social parecem oferecer barreiras ao seu desejo de emancipação como sujeito de sua história.

\section{"Decifra-me ou devoro-te": juventude, questão social e linguagem}

A esquiva traz a problemática da questão social em estreita vinculação com o tema da linguagem, o qual aponta um feixe de instigantes elementos que merecem reflexão. A "linguagem" contribui, por exemplo, para o processo de afirmação de alguns jovens como Lydia, que, independentemente da origem social, tem talento para o mundo do teatro. Comunicativa e bastante assertiva, ela vai "sem meias palavras" em busca do que quer. No caso de Krimo, a linguagem não vem ao seu amparo. Ele fala baixo, articula mal as palavras, não consegue encarnar a personagem. O traje de Arlequim lhe é, portanto, excessivo.

Sua tentativa de conquista amorosa falha e, além disso, o adolescente sofre uma exposição pública, na medida em que a professora tenta a todo custo, embora em vão, fazê-lo sair de si mesmo, demonstrar entusiasmo, de forma a ser capaz de encarnar a personagem e entrar no jogo teatral. Depreende-se dessa cena que, tanto em matéria de amor quanto de linguagem - cinematográfica e teatral, inclusive, segundo o que preconizava Marivaux, por meio da "estética da sugestão" -, há sempre qualquer coisa que não consegue ser dita. Nem tudo é passível de se transformar em palavras. O silêncio, assim, tem seu lugar na comunicação, na expressão dos afetos e também no desfecho de narrativas (ORLANDI, 1997).

Quanto à recepção, o filme deixou - como ficou registrado na internet por meio de críticas e manifestações em fóruns de espectadores - um rastro de incômodo entre os falantes, preciosistas ou não, da língua francesa. Como testemunhou um espectador e internauta: "os atores estão ali para nos fazer rir, nos emocionar, mas também para nos deixar desconcertados" 35 . Muitos espectadores alegaram, com justa razão, certo cansaço, em razão do mergulho nessa viagem quase a um outro "país", próximo geograficamente, mas com um painel bastante diverso em termos de usos, costumes e principalmente da língua. Trata-se, sem dúvida, de um mundo muito diferente para a maioria dos cinéfilos. Tal cansaço envolve, ainda, o enorme esforço despendido para manter a atenção, visto que muitos dos espectadores mal compreendiam o que estava sendo pronunciado pelos atores. Como admitiu outro espectador: "Desde os primeiros momentos deste filme, vemos os adolescentes no meio das suas trocas e bate papos. Eles falam rápido e alto. Não se compreende nada" ${ }^{36}$. A imagem que parece mais adequada para retratar o fluxo do diálogo dessa juventude banlieusarde é: um turbilhão de palavras, mobilizadas, o tempo todo, para regularem conflitos incessantes entre eles.

Analisemos dois motivos constitutivos desse quadro: 1) o elenco foi escolhido entre atores da banlieue francesa, de maneira a permitir à trama maior veracidade e também como estratégia para dar chance e visibilidade a novos talentos, em geral ocultados pela distância física e por camadas de resistência social ao que vem de fora do polo dominante em matéria de cultura $^{37} ; 2$ ) adolescentes da periferia fazem uso de uma gramática e sintaxes que lhes são próprias, introduzem uma série de neologismos, $\log 0$, seu modo de falar está sempre em perpétua mutação. Ademais, articulam insuficientemente as palavras, donde a dicção tende a ser imperfeita. Esse problema poderia ter sido corrigido pelo diretor, mas o intuito era precisamente esse: colocar frente a frente esses "falantes" da grande comunidade linguística francesa - espectadores, de um lado e atores/adolescentes, do outro -, ainda que separados por uma tela de cinema e por uma condição social e étnico-cultural distinta.

Essa aposta ética e estética faz pensar na madrasta de Branca de Neve, que poderia, nessa situação, indagar: "espelho, espelho meu, quem 'fala francês' melhor do que eu?" O espelho, porém, está cindido, quebrado. Assegura, no entanto, em sua unidade, a visão de dois mundos que coexistem, os quais preferem, contudo, evitar-se, nutrindo resistências e preconceitos de parte a parte. A linguagem da juventude da periferia na contemporaneidade se- 
ria, todavia, ao que parece, mais criativa que a da "bela e velha" senhora. Assistir ao filme, bem como encená-lo implica, pois, idas e vindas permanentes ao domínio e à compreensão de duas línguas, as quais tudo concorre para separá-las.

A esquiva evidencia que, na periferia, o francês chega, por vezes, quase a se constituir em uma "língua estrangeira", com o que concorda Guillaume Massart em sua crítica ${ }^{38}$, tal o grau de alteração fonética, decorrente da aproximação com a língua árabe. $\mathrm{O}$ francês falado pela juventude da periferia ganha, assim, outra dicção: pulsa sob nova vibração, tem pouca articulação, é áspero e falado a uma velocidade alucinante. Nem melhor nem pior, apenas diferente, esse francês "mestiço" envereda pelos interstícios da sociedade francesa, irrigando e nutrindo o "falar" das classes populares.

Kechiche não vai, nesse sentido, mostrar-se alheio nem insensível a todas essas transformações. Como declarou outro espectador: "a língua viva prospera aqui embaixo" "39, em alusão à periferia. Logo, o filme em foco vai absorver e dar a conhecer todo esse potencial e pujança linguística, donde a sua rica faceta de documentário, assegurada pela simples incorporação de atores nativos da periferia ${ }^{40}$.

O diretor - que, como ator, também foi preterido mais de uma vez, por seu sotaque beur a trabalhar em ficções cinematográficas que tratavam da obra de Shakespeare - colocou o dedo justamente na ferida. Escolheu não mais esconder essa juventude e mais, destacar o valor das inovações empreendidas pelos adolescentes ao patrimônio cultural linguístico francês. Ao que tudo indica, a cultura francesa hoje não pode mais ignorá-los e se fazer sem eles. De um jeito ou de outro, as águas e seus reflexos espelhados já se misturaram. Resta saber que curso elas vão imprimir doravante nos leitos simbólicos e críticos do Hexágono.

\section{Epílogo - por um novo olhar sobre a juventude das banlieues}

Uma das teses polêmicas do filme irrompe dos lábios da professora: o determinismo da condição social dos indivíduos. O que poderia ser válido na época de Marivaux - e em certa medida ainda o é, socialmente falando da França, onde o peso da tradição e a hierarquização ainda são fortes, apesar da sociedade de massas e da mundialização - foi questionado por movimentos e revoluções que sucederam ao autor de O jogo do amor e do acaso. A mestra reivindica a atualidade do dramaturgo, ao dizer que "disfarces/ máscaras" não são capazes de esconder e mudar quem somos verdadeiramente: "Nós somos marcados por nossa cultura e nossas raízes. Nossa história nos marca de maneira indelével" 41 . Isto vale para o enredo da peça, cujos noivos/amantes visavam driblarse reciprocamente e falham, relativamente, porque, não obstante a mudança de papéis, permanecem quem são: educados e cultos de um lado; extrovertidos, espontâneos e populares, de outro. Vale ainda para explicar o fiasco de Krimo. Vestir o traje de Arlequim não fez dele um ser mais falante e expressivo. Ele continuou a ser exatamente quem era.

Todavia, é importante relativizarmos essa sua afirmação, pois ela naturaliza, mesmo sem o querer, injustiças e desigualdades sociais. Foi contra o determinismo social que vigia na época feudal que a burguesia lutou e, posteriormente, todos os movimentos sociais e socialistas que lutaram por liberdade, autonomia e emancipação dos indivíduos. Outro aspecto que merece cuidado é o da "dimensão culturalista" - essencialista que pode ser associada a essa leitura. Por essa perspectiva, entende-se que se a cultura pode humanizar, suscitar e permitir o exercício da liberdade, pode também, por outro lado, preexistir nos indivíduos, a ponto de moldá-los e aprisioná-los.

Esse é o dilema ao qual alude o debate do "direito à cultura" versus os "direitos culturais". Esses últimos podem ser interpretados em chave puramente localista e particularista de comunidades étnicas, em detrimento de direitos conquistados e assegurados internacionalmente. Equivaleria ainda ao peso das tradições sobre a liberdade de escolha dos indivíduos em construir a sua história e o seu destino, o que constitui demandas essencialmente modernas, franqueadas pelas Revoluções Francesa, Inglesa, Americana, Russa, Cubana e Chinesa, para citar as mais importantes.

Depreende-se, porém, do debate proposto pela personagem da professora, no que concerne à realidade dos estudantes da banlieue, uma triste verdade: a educação republicana, por mais que tenha qualidade, situa-se fora dos marcos da cidadania plena, logo não supre o déficit de recursos materiais e culturais das famílias das classes populares. A liberdade aspirada pelos jovens torna-se, portanto, muitas vezes, limitada pela eventual falta de instrução e de incentivo por parte dos adultos responsáveis e, também, em razão de certos valores familiares, religiosos sobretudo. Não obstante o acesso aos direitos, os horizontes de muitos jovens da periferia francesa são, assim, encurtados social e economicamente, o que corresponde também ao drama dos jovens brasileiros entrevistados no filme Pro dia nascer feliz.

A esquiva é, nesse sentido, uma espécie de manifesto cinematográfico poético-urbano em prol do reconhecimento desses jovens, cheios de vida e de avidez cultural, que merecem mais e melhores oportunidades de desenvolvimento pessoal e social. Este pleito requer, mesmo na França, arrojados projetos de educação, trabalho e cultura para a juventude das classes populares, assim como para a juventude de modo geral. 
O filme faz, sem dúvida, um convite à reflexão sobre cidadania cultural, o que lhe confere um potente caráter político. Consiste num relato engraçado e luminoso, uma pequena ode contemporânea ao direito ao amor e à cultura, um justo testemunho da vida nas cités.

Depois da profunda imersão em tal catarse geracional e linguística, todos os espectadores terminam com a sensação de que valeu conferir essa obra original, dotada de uma temática profunda e filmada com uma câmara agitada, a explorar grandes enquadramentos. Kechiche foi capaz de, delicadamente, pôr a nu algumas das principais fraturas da sociedade francesa. Trata-se enfim de uma bela lição de alteridade, que associa lucidez rara e otimismo.

\section{Referências}

ABRAmo, H. Cenas juvenis. Punks e darks no espetáculo urbano. São Paulo: Scritta, 1994.

A ESQUIVA. Direção: Abdellatif Kechiche. Intérpretes: Osman Elkharraz, Sara Forestier, Sabrina Ouazani, Nanou Benhamou e outros. França: Jacques Ouaniche-Lola Films, 2003. Ficção (117 min.).

ARAN, M.; PEIXOTO JUNIOR, C. A. Subversões do desejo: sobre gênero e subjetividade em Judith Butler. Abril 2007. Disponível em: <http://www.scribd.com/doc/57731836/ ARAN-Marcia-and-PEIXOTO-JUNIOR-Carlos-AugustoSubversoes-do-desejo-sobre-genero-e-subjetividade-emJudith-Butler>. Acesso em: 14 nov. 2010.

BORREIL, J. O verbo ausente. In: SAHEL, C. (Org.). A tolerância. Por um humanismo herético. Porto Alegre: L \& PM, 1993, p. 149-168. (Série Éticas).

BUTLER, J. Le pouvoir des mots. Paris: Éditions Amsterdam, 2004.

2006.

Trouble dans le genre. Paris: La Découverte,

Vivre sa vie. Entretien réalisé par Grégoire Chamayou. In: BENSAID, D. (Org.). Politiquement incorrects. Entretiens du XXIe siècle. Paris, Textuel, 2008, p. 11-128.

CHAUÍ, M. Cidadania cultural. O direito à cultura. São Paulo: Fundação Perseu Abramo, 2006.

DALLËNBACH, L. Le récit spéculaire. Essai sur la mise en abyme. Paris: Seuil, 1977.

EAGLETON, T. A ideia de cultura. São Paulo: Unesp, 2005.
ENCONTRO com Milton Santos ou o mundo global visto do lado de cá. Direção de Silvio Tendler. Brasil: Studio Caliban Produções, 2007. Documentário (89 min.).

ETERSTEIN, C. Le jeu de l'amour et du hasard (1730) - Marivaux. Evreux: Editions Hatier, 1984. (Collection Profil d'une (Euvre).

MAGALHÃES, J. N. et al. (Org.). Construindo memória. Seminários Direito e Cinema. Rio de Janeiro, Faculdade Nacional de Direito, 2009.

MOTA, A. E. O Serviço Social na contemporaneidade: a questão social e as perspectivas políticas. 2000. Disponível em: <www.cfess.org.br/Frentes XXIX Enc Nac CFESSCRESS Anexo2.htm>.Acesso em: 19 nov. 2010.

NOVAES, R. Juventudes cariocas: mediações, conflitos e encontros culturais. In: VIANNA, H. (Org.). Galeras cariocas. Rio de Janeiro: UFRJ, 1997, p. 119-160.

ORLANDI, E. P. As formas do silêncio. São Paulo: Unicamp, 1997.

OSTROWER, F. Criatividade e processos de criação. Petrópolis: Vozes, 1987.

PASQUIER, D. Culture sentimentale et jeux vidéo: le renforcement des identités de sexe. Ethnologie française, v. 40, n. 1 , p. $93-100,2010$.

PORTEVIN, C. et al. Étrangers. Une obsession européenne. Télérama Horizons, Paris, n. 4, avril 2011.

SAÏD, E. Cultura e imperialismo. Tradução de Denise Bottmann. São Paulo: Companhia das Letras, 1995.

Orientalismo: o Oriente como invenção do Ocidente. Tradução de Tomás Rosa Bueno. São Paulo: Companhia das Letras, 2003.

SALES, M. A. (In)visibilidade perversa. Adolescentes infratores como metáfora da violência. São Paulo: Cortez, 2007.

STANILAVSKI, C. La construction du personnage. Paris: Gérard Watelet, 1984.

\section{Notas}

1 Frase de Paulo Cezar Lopes, no documentário Janela da alma, de J. Jardime W. Carvalho, Brasil, 2002.

2 Esse título provém de uma réplica de Arlequim em Ojogo do amor e do acaso, de Marivaux, noAtoII, cena 5, efaz também parte de uma didascália. 
3 Entende-se por "questão social" as expressões da desigualdade social na sociedade capitalista, que evidenciam as condições sociais, econômicas e culturais em que vivem as classes trabalhadoras, no Brasil e no mundo (MOTA, 2000).

4 Conjunto de prédios HLM (habitação de aluguel a preço moderado), em Saint Denis, norte de Paris, onde o filme foi rodado.

5 Técnica narrativa, originalmente atribuída à André Gide e empregada pela primeira vez em 1893.

6 Mais precisamente o escritor e dramaturgo parisiense Pierre Carlet de Chamblain de Marivaux.

7 O cinema é, junto com a fotografia, um meio de comunicação que faz uso da técnica e de novas tecnologias, com vistas à criação de obras de arte. Pela ficção, mas também através de documentários, tem dado a sua contribuição para decifrar a complexidade da questão social e da condição humana na modernidade. É sob esse registro heurístico, antropológico e político, que ele é utilizado aqui como objeto de pesquisa (MAGALHÃES et al., 2009).

8 Representada pela atriz Sara Forestier.

9 Interpretado pelo ator Osman Elkharraz.

10 Não obstante essa observação, o filme não carrega nas tintas da pobreza, ou seja, não possui uma abordagem vitimista. $\mathrm{O}$ enredo desborda, assim, os limites da cité justamente pela universalidade da sua temática. Como bem resume um crítico: "que bela demonstração do que pode ser a vida numa cité, com seus códigos, ritos, sua ternura, seus sofrimentos, suas carências, mas também seu magnífico potencial de riquezas [...]". Disponível em : 〈http://arts-cultures.cef.fr/cinx.htm $>$. Acesso em: 15 mar. 2011

11 Na raiz latina da palavra cultura, colere, encontra-se como referência os verbos cultivar, criar, tomar conta, cuidar. Pode-se, assim, estender semanticamente esta noção para qualificar o "direito à cultura". Em se tratando da juventude, isto condiz com o direito ao tempo do aprimoramento, mais a transmissão de conhecimentos e experiências sociais, com vistas ao estímulo à capacidade de criação de cada um. A "cultura" é, assim, segundo Ostrower (1987), essencial ao desenvol-vimento social, porque tece as "formas de convívio entre as pessoas". Na sociedade de classes, porém, este direito é vivenciado desigualmente, mesmo onde se erigiu um Estado de bemestar social, como na França (CHAUÍ, 2006; EAGLETON, 2005).

12 Esta escolha de cenário não é anódina. Faz pensar tanto no teatro grego clássico ou na época de Shakespeare, quando as representações davam-se à luz do dia e ao ar livre, quanto ainda no espírito de trupe teatral, bastante afeito à comédia italiana a qual Marivaux era discípulo.

13 Interpretada pela atriz Carole Franck.

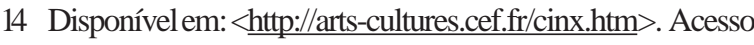
em: 15 mar. 2011.

15 Para quem se interessa pelo assunto, ver o texto Diction et chant (STANILAVSKI, 1984).

16 Disponível em: <http://cinema.fluctuat.net/films/l-esquive/ 801-chronique-une-esquisse-d-amour-les-yeux-dans-labanlieue.html>.Acesso em: 15 mar. 2011.

17 Disponível em: <http://www.webcity.fr/l-esquive/ evenement?nbPages $=2 \&$ debut $=10 \&$ page $=2 \&$ tri $=$ dateD $>$. Acesso em: 15 mar. 2011.

18 População oriunda da África do Norte, compreendendo países como Argélia, Marrocos e Tunísia.

19 Embora seja corrente no debate brasileiro mais recente a referência à existência de "juventudes", a partir de uma influência, dentre outras, das leituras da Unesco, prefiro insistir na terminologia clássica, enxergando nos novos usos conceituais uma tendência culturalista, que fragmenta uma experiência social, a qual, embora marcada por particularidades locais e de classe, é na modernidade dotada de universalidade. Seria expressão, portanto, da unidade na diversidade. Os estudos e pesquisas sobre a juventude urbana, especialmente após a consolidação do processo de globalização, apontam muito mais identidades culturais do que as clivagens sociológicas pretendem. A música, a moda e as redes sociais favorecem hoje a circulação nacional e internacional de hábitos, valores e modelos culturais. Não é exagerado, porém, ao nosso ver, antropologicamente falar em "tribos" e "galeras", conforme Abramo (1994) e Novaes (1997).

20 Cada vez mais, introduz-se no falar descontraído de jovens adultos e adolescentes das classes médias e abastadas do Hexágono. Disponível em: 〈http://www.fredak.com/dico/ dico argot.htm>. Acesso em: 20 fev. 2011.

21 Termoem verlan (originalmente da palavraárabe) que designa os descendentes de imigrantes da África do Norte, nascidos na França e ali residentes. Para mulheres, diz-se beurettes.

22 Prêmio conferido aAbdellatif Kechiche e a Ghalya Lacroix.

23 A filósofa norte-americana sugere o recurso metodológico à categoria de "tradução cultural" como forma de reescrever os direitos humanos, muitas vezes definidos aprioristicamente. Consistiria, pois, numa atualização e redefinição a partir das necessidades dos sujeitos e especificidades históricas, em que a noção de humano 
precisa ser definida diferentemente ou ressignificada (BUTLER, 2008).

24 A propósito da Declaração de Fribourg sobre os direitos culturais, adotada em maio de 2007. Disponível em: $<$ http:// www.aidh.org/ONU GE/Comite Drtcult/declafribourg.htm >.Acesso em: 31 maio 2011.

25 Sobre este debate, conferir as obras de Edward W. Saïd (1996, 2003).

26 A importância do tema no filme e na pesquisa contemporânea são reveladores do lugar dessa questão, ontologicamente falando. Somos todos seres constituídos pela linguagem, diria Judith Butler (2004), para quem a linguagem é dotada da "potência de agir". No entanto, ela chama atenção também justamente para o seu oposto, a "vulnerabilidade linguística", diante de ofensas, injúrias, agressões e preconceito.

27 Interpretado pelo ator e morador da cité Nanou Benahmou.

28 Sylviaé uma jovem aristocrata que quer testar as motivações e o caráter do seu pretendente Dorante. Para isso, ela propõe ao pai trocar de lugar com a empregada Lisette. Dorante tem também a mesma ideia e sugere o mesmo estratagema ao seu empregado Arlequim. O "acaso" interferiu, fazendo com que ambos tivessem o mesmo projeto e se enamorassem um do outro por livre consentimento e não apenas por convenção social. O casal de empregadostambém irá se enamorar.

29 Referência à cena em que eles ensaiam, sentados e sozinhos, a peça ao ar livre, quando Krimo aproveita a ocasião para tentar roubar um beijo de Lydia, a qual termina caindo. A outra cena é a da representação em sala de aula, em que Krimo mal consegue balbuciar as palavras do texto, completamente paralisado diante de Lydia, da professora e do público de colegas.

30 Esse papel é interpretado por Hafet Ben-Ahmed.

31 As relações de gênero são, para Judith Butler (2006), construções sociais históricas, que se impõem como normas e pela repetição. Não obstante, o masculino e o feminino não se encerram nesses moldes, ora manifestando sua contingência ora produzindo, subjetivamente, resistências e diferenças (ARAN; PEIXOTO JUNIOR, 2007).

32 Papel interpretado por Aurélie Ganito.

33 Alguns adolescentes no filme ironizam o teatro como algo démodé, talvez porque a peça em questão fala justamente de sentimentos.

34 A palavra "esquiva" somente ganha pleno sentido no final do filme. Vale resgatar, então, o seu múltiplo e rico significado em francês (l'esquive): ação para fugir de um ataque; retirarse discretamente, sem ser visto; evitar de maneira hábil; escamotear; evitar.

35 E um outro completa: "Finalmente um filme que consegue traçar a vida dos jovens de menos de 18 anos moradores de prédios HLM". Respectivamente, disponíveis em: $\langle\underline{\text { http:// }}$ www.cinefil.com/film/l-esquive > e $<$ http://www.webcity.fr/lesquive/evenement?nbPages $=2 \&$ debut $=10 \&$ page $=$ 2\&tri=dateD>.Acessos em: 15 mar. 2011.

36 Disponível em: $<$ http://arts-cultures.cef.fr/cinx.htm $>$. Acesso em: 15 mar. 2011.

37 Conforme depoimento de Milton Santos: "Mas as outras formas todas de manifestação propriamente culturais não aparecem com essa aura de cultura, que é reservada digamos assim a parcelas já privilegiadas que fazem cultura; os outros fazem outras coisas. A gente não admite dizer imediatamente que o que eles fazem é cultura, porque o que eles fazem é cultura e política ao mesmo tempo" (ENCONTRO, 2007).

38 L'esquive, crítica do filme. Disponível em: <http:// archive.filmdeculte.com/film/film.php?id=721>. Acessoem: 15 mar. 2011.

39 Disponível em: <http://www.imdb.fr/title/tt0338977/ plotsummary >. Acesso em: 15 mar. 2011.

40 À exceção de Sara Forestier, atriz que interpreta a adolescente Lydia, cujo domínio do "neofrancês" lhe vale, na ocasião, o prêmio de Melhor Esperança Jovem Feminina e mais recentemente o prêmio César, pela sua participação na comédia dramática Les noms des gens (França, 2010) - em tradução livre, Onome das pessoas -, o que confirma a aposta feita no seu talento pelaAcademia, em 2005.

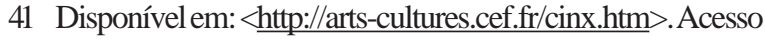
em: 15 mar. 2011

\section{Mione Apolinario Sales}

mionesales@uol.com.br

Doutora em Sociologia pela Universidade de São Paulo (USP)

Professora Adjunta da Faculdade de Serviço Social da Universidade do Estado do Rio de Janeiro (FSS/ UERJ)

UERJ - Faculdade de Serviço Social

Rua São Francisco Xavier, 524 - $8^{\circ}$ Andar

Bloco D - Maracanã

Rio de Janeiro - Rio de Janeiro

CEP: 20550-908 